\title{
How to defuse a demographic time bomb: the way forward?
}

Eye (2017) 31, 1519-1522; doi:10.1038/eye.2017.114; published online 16 June 2017

The pressure of rising demand on ophthalmic services in the United Kingdom, and the negative effect of capacity shortfall on clinical outcomes are well-attested. ${ }^{1}$ With the major ophthalmic conditions of public health interest, cataract, glaucoma, age-related macular degeneration (AMD), and diabetic retinopathy (DR), being strongly associated with increasing age, the capacity/demand disequilibrium is expected to worsen with an ageing demographic. Epidemiological modelling for The Royal College of Ophthalmologists (RCOphth) commissioned Way Forward project predicted that between 2015 and 2035 the United Kingdom will experience a growth in case numbers of about $44 \%$ for glaucoma, $50 \%$ for operable cataract, and 59\% for AMD (https:/ / www.rcophth.ac.uk/standards-publicationsresearch/the-way-forward/). Published projections suggest that diabetic numbers will also rise by $\sim 50 \%{ }^{2,3}$

Rising prevalence is compounded by expansion of cost-effective but labour-intensive treatment options and lower treatment thresholds without a commensurate growth in resources. Human resources are a particular problem with a global shortage of ophthalmologists, ${ }^{4}$ and realisation that recruitment of staff from the health systems of countries with far greater ophthalmic human resource problems than the United Kingdom is no longer ethically acceptable. ${ }^{5}$

A paradigm shift is required in the delivery of ophthalmic care to protect patients. The Way Forward project was constructed to facilitate shared learning as innovations in service design are identified and disseminated. The full reports are available online (www.rcophth.ac.uk/ standards-publications-research/the-way- forward); this article provides a summary of the findings with exemplars.

\section{Way Forward methodology}

A literature review was conducted, and semistructured telephone interviews, offered via lead clinicians, were completed with consultant ophthalmologists responsible for glaucoma $(n=43)$, cataract $(50), \mathrm{DR}(36)$, and AMD (30) from December 2015 to June 2016.

\section{Glaucoma}

\section{Demand management}

Typically $\sim 40 \%$ of community optometrist referrals for suspected glaucoma are false positives $^{6,7}$ and are amenable to reduction by referral filtering schemes. ${ }^{6-9}$ Two-thirds of glaucoma consultants reported such schemes in their locality, so for one-third, the opportunity exists to, at least, start a repeat measures scheme for intra-ocular pressure (IOP)-based referrals.

\section{Pathway redesign}

Optimal utilisation of the decision-making ability of senior ophthalmologists for complex cases is essential. This is not a new concept with early innovators running modified services in the 1990s. ${ }^{10}$ Stratification of cases by risk permits allocation of low-risk cases to either a virtual clinic, or a multi-disciplinary team (MDT) clinic, with optometrists/nurse practitioners/ orthoptists (non-medical health-care practitioners (HCPs)) requesting consultant input only as required. Virtual clinics involve visual acuity (VA), IOP, and visual field data acquisition by HCPs/technicians, often also obtaining disc images, pachymetry, and even gonioscopy. Consultant review of the data/ images is then undertaken (typically 10-12 


$\left.\left.\left.\left.\sum \begin{array}{c}\text { Referral with } \\ \text { Cataract }\end{array}\right\rangle \begin{array}{c}\text { One stop } \\ \text { biometry / pre- } \\ \text { assessment/ } \\ \text { ophthalmologist }\end{array}\right\rangle>\begin{array}{c}\text { First eye } \\ \text { operation \& list } \\ \text { for } 2^{\text {nd }} \text { eye }\end{array}\right\rangle>\begin{array}{c}\text { Review first eye, } \\ \text { do second eye } \\ \text { operation \& } \\ \text { discharge }\end{array}\right\rangle$

Figure 1 The lightest cataract pathway involved no routine review after first or second eye.

patients reviewed per hour) and letters sent to patients to inform them of the outcome.

\section{Task shifting}

Task shifting can be a two-step process. ${ }^{11}$ Once appropriate complexity patients are being managed satisfactorily by MDT in the hospital, the location of this devolved clinical work may be shifted into the community; convenient for patients but potentially more expensive. ${ }^{12,13}$

\section{Cataract}

\section{Demand management}

A survey in England showed that 71/151 commissioning bodies explicitly ration access to cataract surgery despite poor evidence to guide criteria setting, ${ }^{14,15}$ and it being contrary to RCOphth guidelines. ${ }^{16}$

\section{Pathway redesign}

Bilateral cataract patients can be treated with just three hospital visits (Figure 1); safety in this pathway is permitted by easy-access symptom-driven post-operative review, autorefraction guiding second eye lens selection. A less radical change, well established in many units is to discharge uncomplicated second eye cataract patients from theatre. This is an easy win demand reduction, but refractive outcome data collection must be monitored.

\section{Task shifting}

Nine out of ten departments still routinely reviewing post-operative cataract patients use nonophthalmologists. More difficult to replicate perhaps is the one in five departments who has trained HCPs seeing cataract referrals; ophthalmologists only see the patient for surgery. This pathway relies on high-quality MDT members and does not adhere to current RCOphth guidelines.

\section{Efficient surgical service delivery}

Despite the recommendation from RCOphth and Monitor that one cataract operation is carried out every $30 \mathrm{~min}, 17$ the mode number of cases reported at interview was 6 on
$4 \mathrm{~h}$ lists both for training and consultant-only lists. However, five departments routinely scheduled $\geq 10$ cases. The expense of anaesthetists can be saved on dedicated local anaesthetic lists, provided staff have appropriate life support training.

\section{Age-related macular degeneration}

\section{Demand management}

Referral refinement was not a perceived need, but twothirds of departments run virtual AMD clinics (VA/ OCT/photo), and for some, this is their standard initial evaluation for all new referrals to minimise delays for high-risk cases, and discharge of false-positive referrals.

\section{Pathway redesign}

AMD pathways are in a state of evolution nationally. ${ }^{18}$ Almost one-third of departments offer one-stop assessment/injection for first visits, and almost half do for follow-ups.

\section{Task shifting}

Virtual clinics can be quality assured, hence many consultants pass on the virtual review work to trained HCPs. Non-ophthalmologist injection services are commonplace, however over one-third of departments still have all injections given by ophthalmologists. ${ }^{19}$

\section{Diabetic retinopathy}

\section{Demand management}

Repeated local audits showed $>50 \%$ of new DR referrals were for maculopathy that did not require intervention. ${ }^{20}$ Half of the consultants interviewed had virtual review clinics for maculopathy, and in some cases, the screening programme itself has taken on this work. ${ }^{21}$ Screeners time can be freed up by automated computer disease/no disease grading removing $30 \%$ of images from their workload. ${ }^{22}$

\section{Task shifting}

As well as referral refinement, the pool of experienced DR screening graders can be utilised for monitoring treated proliferative disease. ${ }^{23}$ 


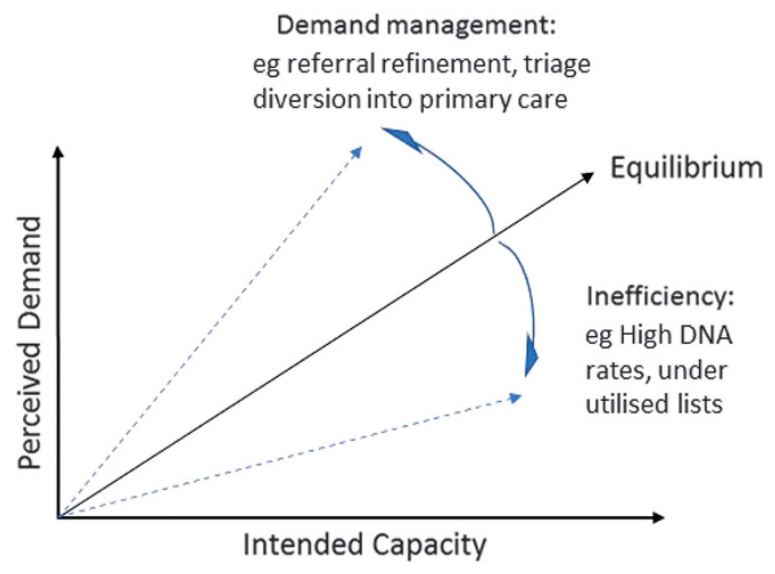

Figure 2 Strategic intentional demand capacity management is essential.

\section{Pathway redesign}

Capacity wastage from failure to attend (DNA) must be minimised using the evidence-based interventions that exist (Figure 2). ${ }^{24}$

\section{Discussion}

The Way Forward project has given some sense of the scale of the future demand facing UK eye departments, and some of the options to deal with this demand already in use by colleagues around the country. Inaction is not an option. It is incumbent on each department in the United Kingdom to identify opportunities for service redesign to maximise efficiency and reduce unwarranted variation. Tasks that can be safely devolved to trained HCPs or areas where technology may offer time savings should also be explored, such that senior ophthalmologists are fully engaged in activities that genuinely require the training, knowledge, and experience that they have, and so that every MDT member, the ophthalmologist included, is operating at the top of their grade.

\section{Conflict of interest}

The authors declare no conflict of interest.

\section{Acknowledgements}

Contribution is acknowledged from the Way Forward Steering Committee and Reference Group: Tom Bremridge, Barny Foot, David Morsman, Rachel Pilling, Richard Smith, John Somner, John Sparrow, Rachel Stancliffe, and Peter Tiffin. The Way Forward project was funded by the Royal College of Ophthalmologists. Subsequent Salary support for JCB is provided by the Queen Elizabeth Diamond Jubilee Trust through the Commonwealth Eye Health Consortium.

\section{References}

1 Foot B, MacEwen C. Surveillance of sight loss due to delay in ophthalmic treatment or review: frequency, cause and outcome. Eye (Lond) 2017; 31(5): 771-775.

2 Waldeyer R, Brinks R, Rathmann W, Giani G, Icks A. Projection of the burden of type 2 diabetes mellitus in Germany: a demographic modelling approach to estimate the direct medical excess costs from 2010 to 2040. Diabet Med 2013; 30: 999-1008.

3 Huang ES, Basu A, O'Grady M, Capretta JC. Projecting the future diabetes population size and related costs for the U.S. Diabetes Care 2009; 32(12): 2225-2229.

4 Resnikoff S, Felch W, Gauthier TM, Spivey B. The number of ophthalmologists in practice and training worldwide: a growing gap despite more than 200,000 practitioners. $\mathrm{Br} J$ Ophthalmol 2012; 96(6): 783-787.

5 Bastawrous A, Hennig BD. The global inverse care law: a distorted map of blindness. Br J Ophthalmol 2012; 96(10): 1357-1358.

6 Henson DB, Spencer AF, Harper R, Cadman EJ. Community refinement of glaucoma referrals. Eye 2003; 17(1): 21-26.

7 Ratnarajan G, Newsom W, Vernon SA, Fenerty C, Henson D, Spencer $\mathrm{F}$ et al. The effectiveness of schemes that refine referrals between primary and secondary care-the UK experience with glaucoma referrals: the Health Innovation \& Education Cluster (HIEC) Glaucoma Pathways Project. BMJ Open 2013; 3. pii: e002715.

8 Bourne RR, French KA, Chang L, Borman AD, Hingorani M, Newsom WD. Can a community optometrist-based referral refinement scheme reduce false-positive glaucoma hospital referrals without compromising quality of care? The community and hospital allied network glaucoma evaluation scheme (CHANGES). Eye 2010; 24(5): 881-887.

9 Devarajan N, Williams GS, Hopes M, O'Sullivan D, Jones D. The Carmarthenshire Glaucoma Referral Refinement Scheme, a safe and efficient screening service. Eye 2011; 25(1): 43-49.

10 Vernon SA, Adair A. Shared care in glaucoma: a national study of secondary care lead schemes in England. Eye 2010; 24(2): 265-269.

11 Holtzer-Goor KM, Plochg T, Lemij HG, van Sprundel E, Koopmanschap MA, Klazinga NS. Why a successful task substitution in glaucoma care could not be transferred from a hospital setting to a primary care setting: a qualitative study. Implement Sci 2013; 8: 14.

12 Spry PG, Spencer IC, Sparrow JM, Peters TJ, Brookes ST, Gray $S$ et al. The Bristol Shared Care Glaucoma Study: reliability of community optometric and hospital eye service test measures. Br J Ophthalmol 1999; 83(6): 707-712.

13 Coast J, Spencer IC, Smith L, Spry PG. Comparing costs of monitoring glaucoma patients: hospital ophthalmologists versus community optometrists. J Health Serv Res Policy 1997; 2(1): 19-25.

14 McLaughlan BWS, Benjamin L, Cassels-Brown A, Smith R. Don't turn back the clock: cataract surgery - the need for patientcentred care. RNIB, RCOphth, UK, 2011.

15 Coronini-Cronberg S, Lee H, Darzi A, Smith P. Evaluation of clinical threshold policies for cataract surgery among English commissioners. J Health Serv Res Policy 2012; 17(4): 241-247.

16 Day AC, Wormald R, Coronini-Cronberg S, Smith R. Royal College of Ophthalmologists Cataract Surgery Commissioning Guidance Development Group. The Royal College of Ophthalmologists' Cataract Surgery 
Commissioning Guidance: executive summary. Eye (Lond) 2016; 30(3): 498-502.

17 MacEwen C, Mascie-Taylor H, Wilton T. Helping NHS providers improve productivity in elective care. Monitor/ RCOphth/British Orthopaedic Association, UK, 2015.

18 Amoaku W, Blakeney S, Freeman M, Gale R, Johnston R, Kelly SP et al. Action on AMD. Optimising patient management: act now to ensure current and continual delivery of best possible patient care. Eye 2012; 26(Suppl 1) S2-21.

19 DaCosta J, Hamilton R, Nago J, Mapani A, Kennedy E, Luckett $\mathrm{T}$ et al. Implementation of a nurse-delivered intravitreal injection service. Eye 2014; 28(6): 734-740.

20 Looker HC, Nyangoma SO, Cromie DT, Olson JA, Leese GP, Black MW et al. Rates of referable eye disease in the Scottish National Diabetic Retinopathy Screening Programme. $\mathrm{Br} \mathrm{J}$ Ophthalmol 2014; 98(6): 790-795.

21 Manjunath V, Papastavrou V, Steel DH, Menon G, Taylor R, Peto $\mathrm{T}$ et al. Wide-field imaging and OCT vs clinical evaluation of patients referred from diabetic retinopathy screening. Eye 2015; 29(3): 416-423.

22 Philip S, Fleming AD, Goatman KA, Fonseca S, McNamee P, Scotland GS et al. The efficacy of automated "disease/no disease" grading for diabetic retinopathy in a systematic screening programme. Br J Ophthalmol 2007; 91(11): 1512-1517.

23 Negretti GS, Vafidis GC. Is it safe to discharge treated proliferative diabetic retinopathy patients from the hospital eye service to a community screening programme? Eye (Lond) 2014; 28(6): 696-700.

24 Thompson AC, Thompson MO, Young DL, Lin RC, Sanislo SR, Moshfeghi DM et al. Barriers to follow-up and strategies to improve adherence to appointments for care of chronic eye diseases. Invest Ophthalmol Vis Sci 2015; 56(8): 4324-4331.

JC Buchan', W Amoaku², B Barnes ${ }^{3}$, A Cassels-Brown ${ }^{4}$, BY Chang ${ }^{4}$, J Harcourt ${ }^{5}$, D Shickle ${ }^{6}$, AF Spencer ${ }^{7}$, SA Vernon ${ }^{8}$ and C MacEwen ${ }^{9}$

${ }^{1}$ International Centre for Eye Health, London School of Hygiene and Tropical Medicine, London, UK

${ }^{2}$ University of Nottingham, Academic Ophthalmology, Eye and ENT Centre, University Hospital QMC, Nottingham, UK

${ }^{3}$ The Royal College of Ophthalmologists, London, UK ${ }^{4}$ Department of Ophthalmology, St James's University Hospital, Leeds, UK

${ }^{5}$ Eye Department, Aberdeen Royal Infirmary, Aberdeen, UK

${ }^{6}$ Leeds Institute of Health Sciences, University of Leeds, Leeds, UK

${ }^{7}$ Manchester Royal Eye Hospital, Manchester, UK ${ }^{8}$ The BMI Park Hospital, Nottingham, UK ${ }^{9}$ Ninewells Hospital, Dundee, UK

Correspondence: JC Buchan, International Centre for Eye Health, London School of Hygiene and Tropical Medicine, Keppel Street, London WC1E 7HT, UK

Tel: +44 (0)11 3243 3144;

Fax: +44 (0)113206 6044 .

E-mail: john.buchan@lshtm.ac.uk 